\title{
A Simulation Model of the Interactions between Power Producers and Customers
}

\author{
Iana Vassileva, Cajsa Bartusch, Fredrik Wallin, Erik Dahlquist, Mälardalen Univ., Västerås, Sweden \\ SNE Simulation Notes Europe SNE 19(3-4), 2009, 67-74, doi: 10.11128/sne.19.tn.09957
}

We have had a strong mechanism for interaction between power production companies and the power trading/supplier companies for a number of years by now. In the future we can expect new types of more interactive communications between single customers and groups of customers towards the energy market companies. We can also expect a stronger demand-side from the customers, e.g. to buy only green energy, only nuclear etc. Power $(\mathrm{kW})$ will be an important parameter aside of energy $(\mathrm{kWh})$ and there will be new possibilities to buy energy when it is as cheap as possible. This may include new applications like charging batteries for your car when the electricity price is low. Differentiation of price may be not only as a direct function of time, but also energy availability like when it is windy, as wind power becomes a major part of many energy systems. Energy storage will be more important and perhaps we will get new possibilities to buy shares in central energy storages, in the same way as space is bought at servers for your applications, photos, webpages etc. Other type of functions may develop as a result of the introduction of individual metering of first electricity and later on hot water and temperature. By metering the individual consumption and billing the exact amount that has been consumed, there will also increase the driving force also to perform energy and load saving actions, e.g. turning off high demand functions like "infra-heating", "large screen TV" and similar, when other usages are on, and the price is high. We expect displays with interaction possibilities in all homes, where you can see your consumption and pricing information. These new type of systems will put new demands on both hardware for supply and software to handle the services/functions. As part of developing this, mathematical modelling of the systems and tests with simulators will be an important tool. Also new soft ware functions will be developed to support the actual services, like simulators giving information on how different actions you make as a user will influence your energy consumption in the future, both short term and more long term. For the more long term case, new investments in new hardware and software may be proposed and evaluated for users in both technical and economic terms.

In this paper the system aspects including the costs is analysed through a simulation model. This includes the physical system as well as the user behaviour and possible effects of different price models, like a combination of $\mathrm{kW}$ and $\mathrm{kWh}$. The effect on the users, the distributors and the power producers are evaluated.

\section{Background}

The total energy demand is approximately $400 \mathrm{Wh} / \mathrm{y}$ in Sweden. From this the total electricity demand is $146 \mathrm{TWh} / \mathrm{y} .45 \mathrm{TWh} / \mathrm{y}$ of this is used to heat buildings. The electric power production is primarily made by Nuclear power $70 \mathrm{TWh} / \mathrm{y}$ and Hydro power 70 $\mathrm{TWh} / \mathrm{y}$. The maximum electric power is $27500 \mathrm{MW}$, but this capacity is only needed when it is really cold outside, or large amounts of electricity is exported to other countries. Principally $9000 \mathrm{MW}$ is used for peak load when it is very low outdoor temperatures. It may also be possible to import power during peak load, but then the capacity of the transmission lines will be the limiting factor.

The settlements around the cities are expanding. This leads to a need for new cables and other equipment like transformers or to limit the maximum power, e.g. by differentiated prices.
In general, the potential for energy reduction can be promoted in three main sectors of energy users: in households, office buildings, and industry. This potential can be achieved by implementing various techniques and initiatives oriented at changing consumers' behaviour in the direction of more efficient energy use.

There are economic incentives for limiting peak loads. Old hydro power plant operation cost is $20-$ $30 \mathrm{SEK} / \mathrm{MWh}$ in Scandinavia. The cost for old nuclear power is approximately $160-200 \mathrm{SEK} / \mathrm{MWh}$, while old combined heat and power plants (CHP) have a cost of approximately $180-250$ SEK/MWh. New wind power will have a total cost of some 300$700 \mathrm{SEK} / \mathrm{MWh}$ while new coal condensing has an installed cost of $30000 \mathrm{SEK} / \mathrm{KW}$ to be compared to $15000 \mathrm{SEK} / \mathrm{KW}$ just five years ago.. 


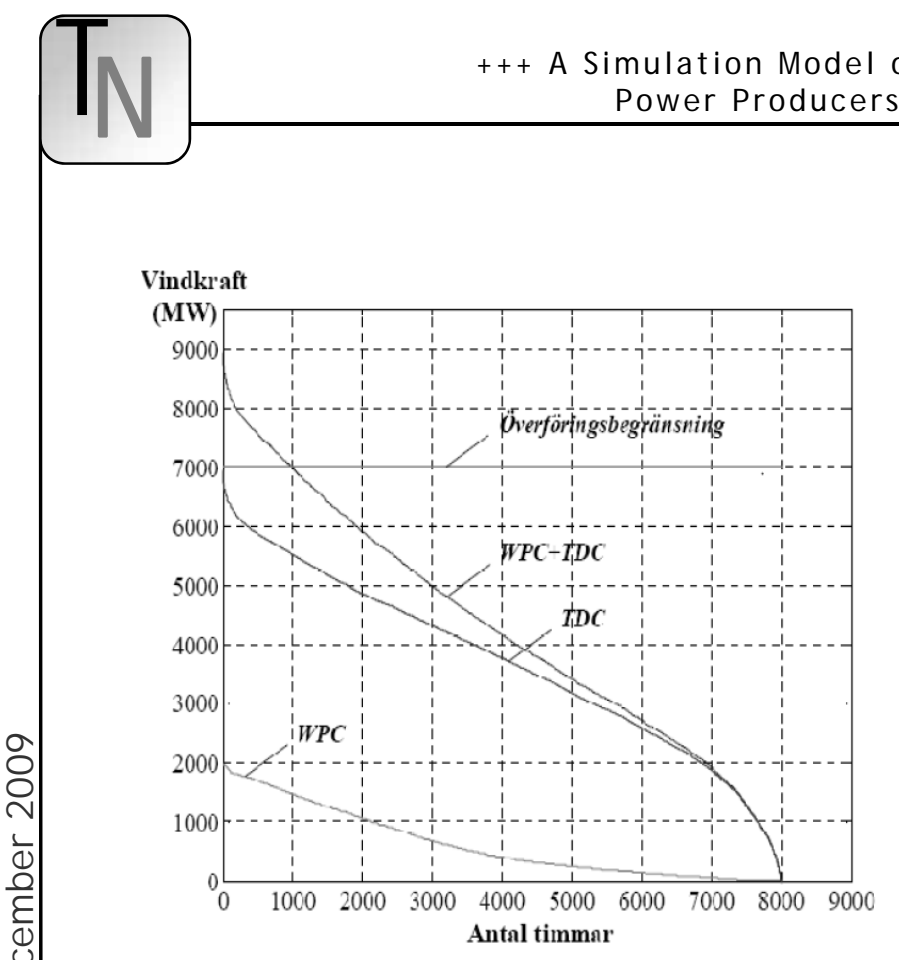

Figure 1. Number of hours per year at a certain power level for a maximum $2000 \mathrm{MW}$ wind power park (WPC). TDC is the actual total power transmitted from northern Sweden to the Stockholm- Malardalen area. The WPC+TDC would be the total if $2000 \mathrm{MW}$ wind power was installed. $7000 \mathrm{MW}$ is the maximum transmission capacity today. The diagram is from the report by [2] Sveca and Söder [2002].

This means some 600- 800 SEK/MWh electric power. The new natural gas (NG)CHP with a combined cycle in Malmö costs approximately 50000 SEK/MWel. The figures were recently calculated by [1] Swedenergy (2008).

What we can see from this is that wind power has a major interest from a cost point of view. A problem still is that the wind intensity is not correlated to the demand for electricity. In figure 1 we can see a diagram showing power output at different level as a function of the total number of hours at this production level per year.

The other end of the power chain is represented by the energy consumers. The consumption patterns vary very much between different users. In Figure 2 below it is possible to see variations in apartments in Vasteras during 2005-2006. What we can see from this is that the electricity consumption for apartments heated by in this case district heating, the electricity demand is not at all correlated to the size of the apartment. The number of people in each apartment is also roughly the same [3] Vassileva et al (2008).

If we look at single houses [4] Bartusch et al (2008) the situation is similar. The variation between different houses does not correlates to the number of persons living in them (figure 3).
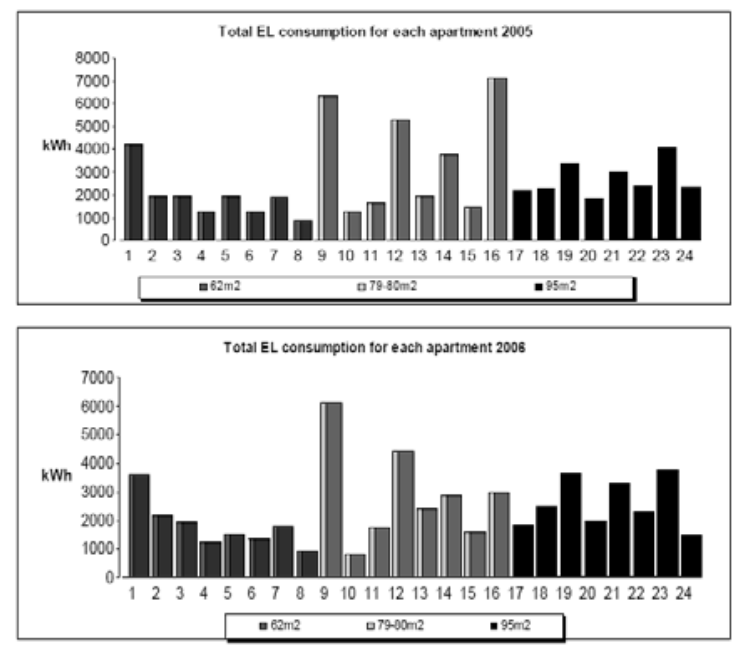

Figure 2. Electricity consumption patterns in apartments with district heating. The first 8 apartments are $62 \mathrm{~m}^{2}$, next $879-80 \mathrm{~m}^{2}$ and last $896 \mathrm{~m}^{2}$

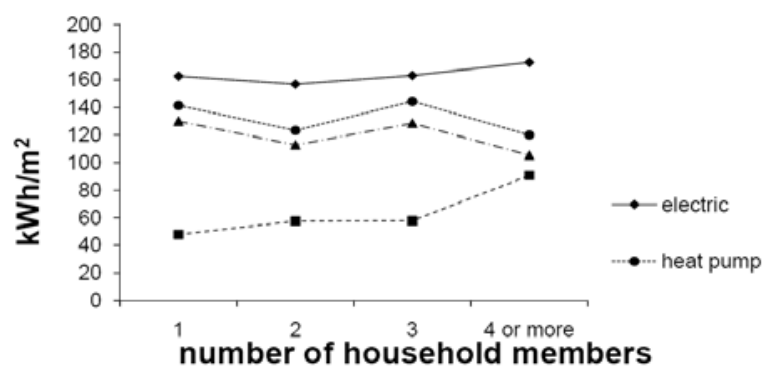

Figure 3. The energy consumption correlated to the number of inhabitants in single houses for households with different type of heating systems: direct electric, electric with heat pump, combined electric and biofuel stove and non-electric

It is also interesting to see that households with direct electric heating have almost the same energy consumption as those with a combined heating system. Only for houses with non-electric heating we see some correlation for very large families compared to those with fewer household members.

It is also interesting to see that the correlation to other factors like size of the house is low, as shown in figure 4.

If the correlation factor had been around 1.0, there would have been a clear correlation, while here it is almost 0 for combined systems, which shows absolutely no correlation, and as highest 0.367 for direct electric heating, which is a very weak correlation. In [5], [6] we can see other similar data presented. 


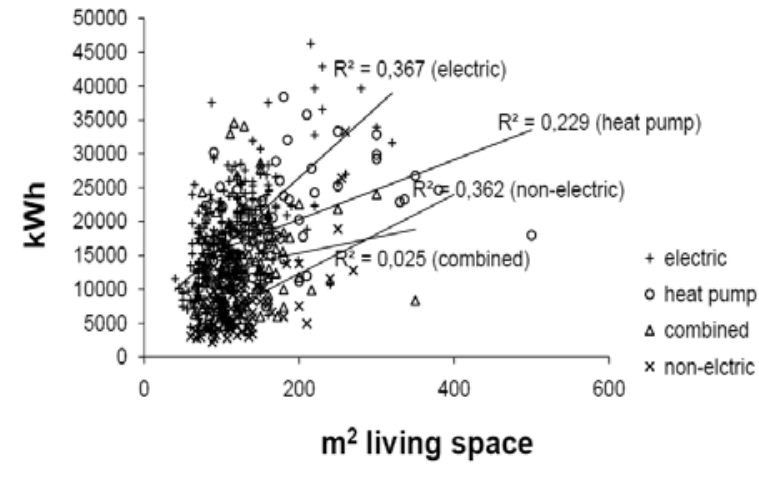

Figure 4. Correlation between electric power consumption as a function of the size of single houses with different heating systems: direct electric, electric with heat pump, combined electric and biofuel stove and nonelectric

The conclusion from this is that the individual behaviour is the most significant factor for the energy consumption. This leads to both advantages and disadvantages. The negative part is that it is difficult to perform direct predictions from data based on number of persons in a household, type of house, size etc. The positive part would be that behaviour can be changed. There are different incentives that can drive the behaviour in the correct direction, e.g. energy prices and environmental issues. Information and improvement of knowledge could also give positive effects.

We now will look at different energy systems and give a frame work on the correlation between different energy systems and how the effect of incentives could affect the systems.

\section{Purpose with the simulations}

The simulation model includes production facilities as sources, and sometimes also with storage capacity, transmission and distribution including loss calculations, and consumption by industry and households/offices.

Starting with the power production we include wind power plants, solar power, nuclear power, hydro power and thermal power plants. For the storage the focus is on hydro power, where pumps can be used to lift water back up to storages during low demand times. Also local small scale storages are assumed, e.g. cars and batteries. At the household side we assume different consumption patterns depending on time of the year, week, and day. Also individual differences are included.
The purpose of the model is to investigate how the losses will depend on different production conditions, especially the varying power supplies like wind and solar power. The simulations also considers how variations in the consumption pattern may influence the energy system, and what peak load cuttings would mean to the system.

\subsection{Simulation model}

The electric power in a power station is normally produced as a turbine drives a synchronous generator. A voltage is produced, as well as a current. If we have the new type of combined generator and transformer, the powerformer, we can produce a high voltage like $130 \mathrm{kV}$ directly.

Otherwise, the produced voltage will be lower, and a transformer will bring it up to the wanted level before the transmission to the customers. Transmission lines are normally $130 \mathrm{kV}$, but can be also $400 \mathrm{kV}$, or even higher, in the national transmission lines. When the power reaches the customers, some industry or group of households or offices, the voltage is taken down to $380 \mathrm{~V}$. We normally have three phases, with $220 \mathrm{~V}$ or $110 \mathrm{~V}$ single phase finally $-220 \mathrm{~V}$ in Scandinavia.

In most transmission lines we use three phases. If we feed a symmetric three phase voltage, this can be seen as in figure 5 .

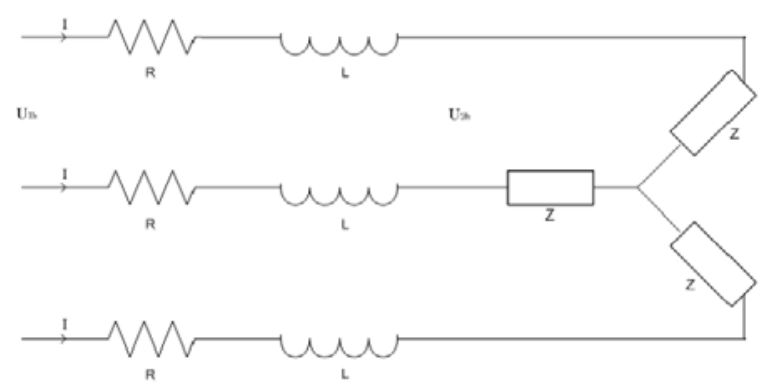

Figure 5. Three phase load with three phase feed, using a $\mathrm{Y}$ - connection

In the figure $R$ is the resistance in each cable; $L$ is the inductance and $Z$ the impedance. $U$ is the potential difference between the phases. The potential drop between two phases from feed to load is given by:

$U_{1 h}-U_{2 h}=I \times \sqrt{3} \times\left(R \cos \varphi_{2}+\omega L \sin \varphi_{2}\right)$

$\varphi_{2}$ is the shift between the phases. This is positive at inductive load, that is if $U_{2}$ is before $I$ in the phase. 
For a copper transmission cable, the resistance is $1,7 \Omega / \mathrm{km}$ if the area of the conductor is $10 \mathrm{~mm}^{2}$, while $0,17 \Omega / \mathrm{km}$ if the area of the conductor is $100 \mathrm{~mm}^{2}$. The inductance $L$ is almost independent of the conductor material for conductors up in the air, as long as the distance between the conductors is significantly larger than the diameter of the conductor.

At $50 \mathrm{~Hz} X=\omega L=$ ca. $0.4 / \mathrm{km}$, phase. Normally $L$ can be neglected compared to the resistance $R$. Then also the term $\omega L \sin \varphi_{2}$ can be neglected.

The loss in the conductor line due to the resistance is now given by:

$$
P_{f}=R \times I^{2} \times W
$$

where $P_{f}=$ resistive losses, $R=$ resistance in one conductor, $I=$ current and $W=$ number of conductors. There are also other types of losses due to turbulence and hysteresis in metallic shields and losses in insulation materials, but these can normally be neglected.

A more important factor with respect to transmission losses is due to reactive power. The active power in $\mathrm{AC}$-current is given by:

When $\cos \varphi=1$, that is when the shift between the phases $\varphi=0$, we have a maximum power transmission. When the phase shift increases, it will not be possible to transport as much current and power as before. We can compare to a beer bottle. If we have a lot of froth (=reactive power) we cannot fill the bottle with beer (= active power). Asynchronous motors or drives will produce reactive power. This can be counteracted by using a synchronous motor or capacitors. This is called reactive power compensation.

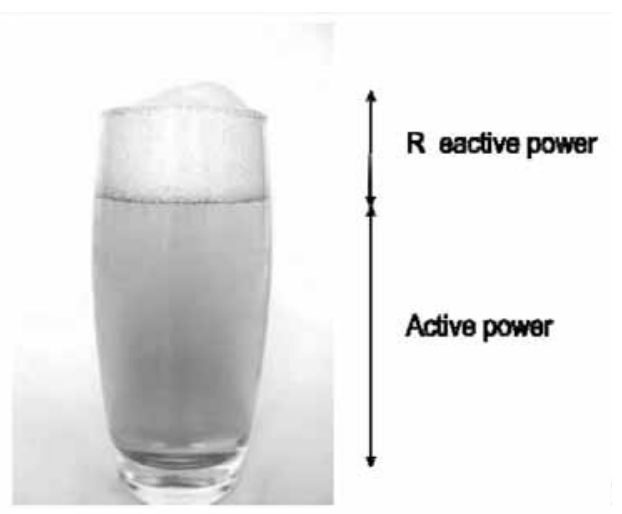

Figure 6. Illustration of reactive and active power by a glass of beer.
We do not include reactive power compensation in these calculations, typically this could improve the capacity by approximately $15-20 \%$.

It can also be interesting to look at transmission and distribution losses in some different countries presented by [7] (World Bank 2002): World-wide 9\%, Sweden, US, China 7\%, Benin 71\%, India and Iran $18 \%$, Mexico $15 \%$ (The data is for the year 1998).

\section{From the simulation and discussion}

A simulation model has been made according to what has been described above. We now will use it for some system calculations. For Sweden hydro power is of major importance, and thus we start with a comparison of a system where we produce $300 \mathrm{MW}$ electric power from a hydro power plant $1000 \mathrm{~km}$ away from where it will be utilized. We then compare this system to a system with a maximum $300 \mathrm{MW}$ wind power plant at the same site.

A system where as much as possible is produced is compared to one where we maximize the production from the wind power plant and then use the hydro power plant as a buffer system. In the first system we also look at the possibility to use the wind energy to pump water back to the hydro power dam when the demand for power is low.

First we look at the transmission line. For a 300 MW transmission line we assume a cable with 2000 mm area of copper. This corresponds to a $50 \mathrm{~mm}$ diameter cable. The resistance is approximately 0.0085 $\Omega / \mathrm{km}$. For a $1000 \mathrm{~km}$ line then the resistance will be $8.5 \Omega$. The current $\mathrm{I}=300000 \mathrm{KW} /(\sqrt{3} \times 400 \mathrm{kV})=$ 433 A.

The power losses $P_{f}=8.5 \Omega \times 433 \mathrm{~A}^{2} \times 3=4.8 \mathrm{MW}$ or $\mathbf{1 . 6 \%}$ losses. For a $500 \mathrm{~mm}$ area copper cable the losses would be $P_{f}=34 \Omega \times 433^{2} \times 3=19 \mathrm{MW}$ or $\mathbf{6 , 3 \%}$. If we used the transmission line for a constant load of only $75 \mathrm{MW}$ instead, the following losses would occur:

The current is $I=75000 \mathrm{KW} /(\sqrt{3} \times 400 \mathrm{kV})=\mathbf{1 0 8 A}$ and the power losses $P_{f}=8.5 \Omega \times 108^{2} \times 3=0.3 \mathrm{MW}$ which gives $\mathbf{0 . 4 \%}$ losses using the $50 \mathrm{~mm}$ diameter cable $\left(2000 \mathrm{~mm}^{2}\right)$. If we instead used a smaller cable with $25 \mathrm{~mm}$ diameter $\left(500 \mathrm{~mm}^{2}\right)$ the losses would be $P_{f}=34 \Omega \times 108^{2} \times 3=1.2 \mathrm{MW}$ which gives $1.6 \%$ losses. 
With a $18 \mathrm{~mm}$ diameter $\left(250 \mathrm{~mm}^{2}\right)$ the losses would be $P_{f}=68 \Omega \times 108^{2} \times 3=2.4 \mathrm{MW}$ which gives $\mathbf{3 . 2 \%}$ losses. For an $11 \mathrm{~mm}$ diameter cable, the losses would be $8 \%$.

It can also be interesting to see how the cost for cables of different dimensions relate to reduced losses during the transmission. If we just look at the copper cost for the cable the price per $\mathrm{kg}$ was $49 \mathrm{SEK} / \mathrm{kg}$ May 2008. For the $50 \mathrm{~mm}$ diameter cable and 1000 $\mathrm{km}$ the investment cost will be for the copper in the cable $1000000 \mathrm{~m} \times\left(0,025^{2} \times \pi\right) \times 8900 \mathrm{~kg} / \mathrm{m} 3=17470 \mathrm{ton}$ $\times 49000$ SEK/ton $=856$ MSEK. For a $25 \mathrm{~mm}$ diameter cable it will be 214 MSEK and for the $18 \mathrm{~mm} 111$ MSEK.

If we now look at the cost for the losses, $0.4 \%$ losses corresponds to $0.004 \times 75 \mathrm{MW} \times 8700 \mathrm{~h} / \mathrm{y} \times$ $250 \mathrm{SEK} / \mathrm{MWh}=0.65 \mathrm{MSEK} / \mathrm{y}$ if we assume the price per MWh to be 250 SEK, while $8 \%$ losses corresponds to $13 \mathrm{MSEK} / \mathrm{y}$. If we capitalize the investment cost to an annual cost with annuity 0.125 respectively summarize this cost over 10 years, and compare to the annual cost for the losses.

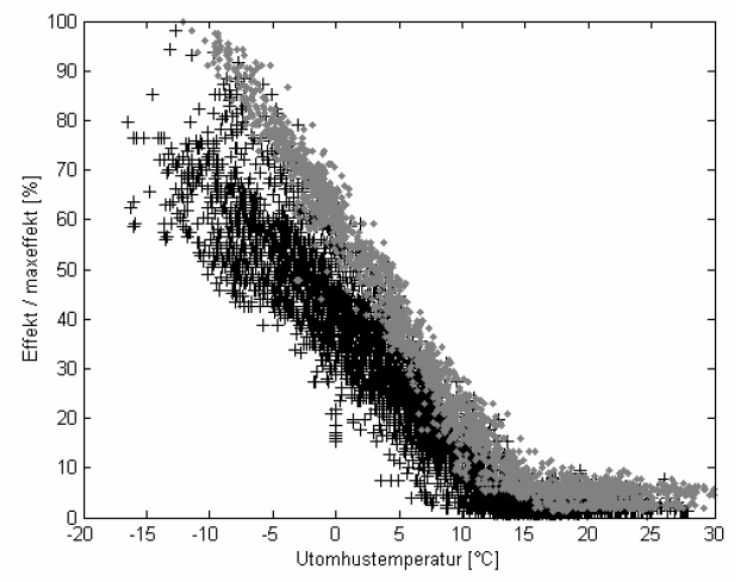

Figure 7. Heat power as a function of out-door temperature in Stockhom for offices during working days (red) compared to Saturday/Sundays (black) [9] [Kvarnstrom et al 2007].

A three phase transformer costs approximately 150 SEK/kVA. For $75 \mathrm{MW}$ the investment cost will be $=$ $75000 \mathrm{kVA} \times 150=11 \mathrm{MSEK}$ and for $300 \mathrm{MW}=$ 45MSEK.
For reactive power compensation capacitors can be used. According to [8] Hume et al [2007] the cost for capacitors are $\$ 16,480$ / MVAR for a dual bus connected capacitor at $220 \mathrm{kV}$ or $110 \mathrm{kV}$ (based on 2006 ODV information published by Transpower with a CPI of 3\%) while a distribution power factor correction capacitor will cost about $\$ 34700$ per MVAR for switched $11 \mathrm{kV}$ zone substation capacitors.

For 75 MVAR (MW) that means in case of distribution power correction 34690\$/MVAR $\times 6.3 \mathrm{SEK} / \$ \times$ 75MVAR $=16.4 \mathrm{MSEK}$. In relation to the other costs this is quite small. These cost have not been included in our calculations below, but can be added if reactive power compensation is to be included.

For a complete transmission line the cost is around $5000 \mathrm{SEK} / \mathrm{kVA}$ according to estimates done for an $800 \mathrm{MW}$ transmission line at $400 \mathrm{kV}$. If we extrapolate from this we get $300 \mathrm{MW} 1500 \mathrm{MSEK}$, and for 75 MW 375 MSEK.

Lately the electricity price has passed 650 SEK/MWh and it is predicted to pass 1000SEK/MWh perhaps already during the summer 2008 due to a strong demand on coal from China driving the price, and problems with transmission lines from Norway.

With these figures the incentive to reduce losses is increased even further. If the price does not pass 1 $000 \mathrm{SEK} / \mathrm{MWh}$ now, it probably will do so within a foreseeable time horizon.

If we now look at a system where we have a combination of $300 \mathrm{MW}$ hydro power and maximum 300 MW wind power, a maximum capacity of $600 \mathrm{MW}$ would be needed. If we instead make a transmission line with the maximum capacity of $400 \mathrm{MW}$, the investment cost is reduced significantly. When there is a surplus capacity of wind power compared to the demand this may be used to pump water backwards up to the dam.

The investment cost for the transmission line with respect to copper will be reduced from 866 to 577 or by 290 MSEK, and if we take the total cost for the transmission line from 3000 to 2000 MSEK, or 1 000 MSEK. With an annuity of 0.125 this gives an annual cost reduction by $125 \mathrm{MSEK} / \mathrm{y}$ for the investment cost. 
At the same time the transmission losses are reduced during the maximum load conditions, but increased to some extent when there is no wind at all. In the mountain areas the winds are quite good, and we assume that we can have maximum capacity $300 \mathrm{MW}$ $20 \%$ of the year and 75 MW $60 \%$ of the year. If we operate at maximum capacity all the time, the transmission losses for this then become $300 \times 8760 \times 0.2$ $\times 0.016=8410 \mathrm{MWh}$ respectively $75 \times 8760 \times 0.6 \times$ $0.003=2365 \mathrm{MWh}$. The total losses will sum up to $10775 \mathrm{MWh}$, to a value of $7 \mathrm{MSEK} / \mathrm{y}$ at the electricity price $650 \mathrm{SEK} / \mathrm{MWh}$.

If we run at maximum load, $100 \mathrm{MW}$, we instead get $100 \times 8760 \times 0.2 \times 0.0053=929 \mathrm{MWh}$, respectively, $75 \times 8760 \times 0.6 \times 0.003=2365 \mathrm{MWh}$. The total losses then becomes $3294 \mathrm{MWh}$ to a value of 2.1 $\mathrm{MSEK} / \mathrm{y}$.

On the other hand, we will lose some of the electricity due to losses during the pumping in the pump plant. The pump will have an efficiency of $65 \%$, which means a loss of $200 \mathrm{MW} \times 8760 \times 0.2 \times 0.35=$ $122640 \mathrm{MWh}$ or a value of $80 \mathrm{MSEK} / \mathrm{y}$.

This shows that building a smaller transmission capacity gives a saving of $125 \mathrm{MSEK} / \mathrm{y}$ but losses in the pump power plant gives losses $(80-(7-2))=$ $75 \mathrm{MSEK} / \mathrm{y}$. Still it can be a feasible solution to utilize the excess wind for pumping water instead of sending it directly to the transmission line. This solution also will make it possible to balance huge amount of wind power as otherwise we will run into problems with transmission of the electric power long distance.

Today the total power transmission capacity from northern Sweden is $7000 \mathrm{MW}$, but with large amount of installed wind power the capacity will be too low. If we go back to figure 1 , we can see that there is a problem already with the ongoing expansion with some $2000 \mathrm{MW}$ wind when there are strong winds, and high demand, during approximately 1000 hours per year.

The energy used in households and offices is significantly higher during working days due to an increased ventilation, although the heat demand principally should be lower when you have many people, computers and other heat sources "on". This also gives an increased electric power demand for the ventilation.
We have already shown how the reduction of the peak loads is reducing the capital cost on the transmission lines, but also how the reduction of losses gives additional earnings, when the total transfer of power is reduced in an existing line. If we reduce the total peak power from 600 to $400 \mathrm{MW}$ the transmission capacity can be reduced as shown, with annual savings of $125 \mathrm{MSEK}$ for capital costs. If we also reduce the time when the maximum capacity is utilized, additional reductions in losses are gained in the range of 1 - $10 \mathrm{MSEK} /$ year, as shown earlier.

An alternative approach is to keep the transmission of power from the north at as constant level as possible, and then compensate the variations in the demand locally. In this case we can have both local storages like batteries as well as local production of electric power and/or heat. If we produce as much wind power and solar power as possible, when available, batteries in plug in cars can be interesting as the energy storage media. If we assume that the battery is a lead battery like the common ones in cars, the capacity we can store is $30-40 \mathrm{Wh} / \mathrm{kg}$ and the efficiency $70-$ $92 \%$.

The number of cycles for a battery is for this type some $500-1000$ cycles, and the life time $3-20$ years, depending on the operating conditions. For a Litium-ion battery the capacity may be $160 \mathrm{Wh} / \mathrm{kg}$ and the efficiency is $99.9 \%$, and the number of charging cycles may be around 1200 cycles during a life time of $2-3$ years. There are also some new alternatives that may prove to be very interesting in the future.

The company EEstor claim that they can charge their double layer capacitor system in five minutes with 52 $\mathrm{kWh}$ in a $152 \mathrm{~kg}$ heavy (33 liter) unit. This operates at $3500 \mathrm{~V}$, which makes this possible. This means 200 $-300 \mathrm{Wh} / \mathrm{kg}$, and the efficiency is $95 \%$ in the experiments performed. The car they have tested on can travel $480 \mathrm{~km}$ with one charging $(52 \mathrm{kWh})$, which means $1.3 \mathrm{kWh} / 10 \mathrm{~km}$. The target price for such battery is $\$ 2100$ (12 600 SEK), but right now it is $\$ 3$ 200 (19 200 SEK). If we assume the life time will be five years and we travel distance of $10000 \mathrm{~km} / \mathrm{y}$, the cost per $10 \mathrm{~km}$ would be with an annuity factor 0.2 only $3.8 \mathrm{SEK}$. If we add the cost for the electricity 1.3 $\times(1 / 0.95) \times 1 \mathrm{SEK} / \mathrm{kWh}=1.4 \mathrm{SEK}$ the total cost would be $5.2 \mathrm{SEK} / 10 \mathrm{~km}$, which is about half the cost that we pay for gasoline. 
If we just use existing lead batteries, the cost for a battery with the capacity $2,6 \mathrm{kWh}$ is $2000 \mathrm{SEK}$ with the volume 30 liters, and the weight $65 \mathrm{~kg}$. If we want a transportation distance of at least $150 \mathrm{~km}$, it means $15 \times 1.3=19.5 \mathrm{kWh}$, with a price of some $19.5 \times$ $2000 / 2.6=15000$ SEK. This would mean with an annuity of 0.2 and $10000 \mathrm{~km} / \mathrm{y}$ only $3 \mathrm{SEK} / 10 \mathrm{~km}$. This means that even the batteries of today could be economic, although the weight would be some 450 $\mathrm{kg}$. With a Litium -Ion battery the battery weight may be only $100 \mathrm{~kg}$ for the same capacity, but the life time probably shorter.

From this we can make a simulation where we charge the batteries while the price of electricity is low, that is when the demand is lower than the available capacity normally. If you have your own photo voltaic solar panel this would be when there is day-light. If you buy power from the grid, this will be the case when it is windy and wind power production is high, or when the general demand is low. The first case with your own production when it is day-light will reduce the demand from the grid during the summer half of the year, while the demand will be higher during the winter months.

If you have electric heating, this can be compensated by using a pellet burner or wood stove for heating instead, at least when the electricity price is high. For a house that changes the electric heating system with full load to one with reduced electric load including e.g. pellet boiler goes from approximately $9 \mathrm{~kW}$ to 3 $\mathrm{kW}$ maximum electric load. How far the new maximum load will last depends of various conditions. For a house with electrical heating it will be during very cold winter time problems occurs. During the last 20 years, this has been very rare in south and mid Sweden, but normally at least $2-3$ days per winter, when it is significantly below $-10^{\circ} \mathrm{C}$.

The power consumption as well as the wind energy production is seen in the figure 8 below. Here we can see that the normal summer load is around 10000 MW, while approximately 20000 MW during the winter. There are few peak loads up to $27000 \mathrm{MW}$ during very cold days. We can see that it is more wind power produced during the winter, but there are also periods with almost no wind even winter time. Still, there should be a possibility to reduce the power consumption by $30-50 \%$ by introducing better incentives to bring down peak loads.
If we look at the short term variations we can see that these are within $2500-5000 \mathrm{MW}$ year around, and this variation can be handled with short term storages. This would reduce the need for transmission and thus also reduce the losses.

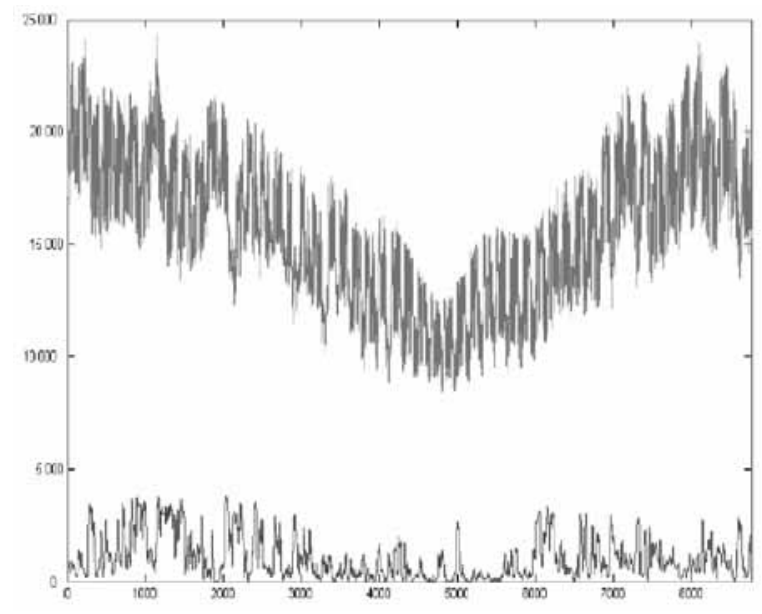

Figure 8. Consumption of electric power(upper) respectively production of power from wind during 2007.

\section{Conclusions}

In this paper we have shown how the existing electric power consumption pattern looks like and what the consequences would be if we could change the consumption pattern through good incentives. The peak load can be reduced by some $30-50 \%$ and the short term variation by some $10-20 \%$ over the year. For the calculation a simulator model has been used. Here we can see how the optimal system could look like under different assumptions.

This paper presents existing electric energy consumption patterns and discuss consequences if these patterns could be changed through different initiatives. The peak load can be reduced in two different perspectives, long term and short term with approximately $30-50 \%$ and $10-20 \%$, respectively.

The calculation steps for a simulator model are presented together with a discussion of optimal energy system design choices. This proposed simulator will form a powerful tool to optimize processes and use of resources. 


\section{References}

[1] Swedenergy. Statistics. 2008.

[2] Sveca J., Söder L.: Wind power integration in power systems with bottleneck problems. VIND-2002 conference in Malmö, November 6-7, 2002.

[3] Vassileva I., Bartusch C., Dahlquist E.: Differences in electricity and hot water consumption in apartments of different sizes. International Conference on Green Energy with energy management and IT, Stockholm, Sweden, March 12-13 2008.

[4] Bartusch C., Odlare M., Wallin F., Dahlquist E.: Electricity consumption and load demand in single-family houses. International Conference on Green Energy with energy management and IT, Stockholm, Sweden, March 12-13 2008.

[5] Widén J., Lundh M., Vassileva I., Dahlquist E., Ellegård K., Wäckelgård E.: Constructing load profiles for household electricity and hot water from time-use data - modelling approach and validation. Submitted to Energy and Buildings Journal. 2008.
[6] Lundh M., Vassileva I., Dahlquist E., Wäckelgård E.: Comparison between hot water measurements and modelled profiles for Swedish households. Eurosun October 2008, Portugal, 2008.

[7] UN, World Bank Development Indicators 2002.

[8] Hume D., de Silva R.: System Studies Group NZ Ltd: Relative Power Factor Correction costs. October 2007. Transmission Electricity Commission. 2007.

[9] Kvarnstrom J., Dotzauer E., Gollvik L., Andersson C.: Lastprognoser för fjärrvärme (Load forecasts for district heating). Värmeforsk Report (in Swedish) 2007.

Corresponding author: Erik Dahlquist, Mälardalen University, Västerås, Sweden erik.dahlquist@mdh.se.at

Received \& Accepted: SIMS 2008

Revised: Juli 7, 2009

Accepted: September 10, 2009 